\title{
CONTROL CONCEPT FOR A GREASE LUBRICATED HYDROSTATIC BEARING
}

\author{
Igor Mass $^{1 *}$, Andreas Hoppermann ${ }^{1}$, Hubertus Murrenhoff ${ }^{2}$ \\ ${ }^{1}$ Hochschule Niederrhein, Faculty of Mechanical and Process Engineering, Germany \\ ${ }^{2}$ RWTH Aachen University, Institute for Fluid Power Drives and Systems (IFAS), Aachen, Germany \\ * Corresponding author: Tel.: +49 2151822 5071; E-mail address: igor.mass@hs-niederrrhein.de
}

\begin{abstract}
In industrial practice greases are mainly used as lubricants in hydrodynamic plain bearings and roller bearings. The use in hydrostatic bearings is avoided due to the difficult controllability. One reason is the complex non-Newtonian flow behavior of greases. The motivation for this paper is the use of greases to increase the efficiency of hydrostatic bearings. The assumption is that the so-called yield stress of consistent greases can lead to self-sealing behavior in the bearing under stationary operation conditions. Assuming a volume-flow-free operation of the bearing, a concept for the active control of the sealing gap height and thus the bearing stiffness was developed. The concept idea is the use of a second medium with Newtonian characteristic for pressure transfer. The grease and the pressure control fluid are structurally separated. The grease is induced in the shortest possible way into the bearing pocket to keep the pressure losses as low as possible. The results of test bench investigations indicate the feasibility of a gap height control with very high bearing stiffness under use of highly consistent greases and initiate further investigation on non-stationary operation.
\end{abstract}

Keywords: Hydrostatic bearing, Bingham Fluid, Grease rheology

\section{INTRODUCTION}

Hydrostatic bearings typically operate under fluid friction in the entire movement process of machine elements. This is conditioned due to the application of a hydrostatic pressure inside socalled bearing pockets by an external pump. Conventional hydrostatic bearing designs include the bearing pocket geometry, the sealing gap ring and the lubricant. The design of such a bearing type is usually carried out by an optimization approach in which the necessary pump power is compared with the friction power for continuous movements [1].

Hydrostatic bearings have a number of advantages compared to other bearing variants because of their operation principle. This includes a wear-free operation (this only affects the actual bearing and not the entire periphery which is necessary for operation), a very low coefficient of friction, no static friction and thus no stick-slip effect, high stiffness and good damping properties [2].

A major disadvantage of this type of bearing is the complex periphery, which is necessary for the operation of the bearing. At least one pump needs to run constantly during operation in order to build up a defined volume flow and pressure.

\subsection{Field of application}

The main function of the bearing in applications, which are characterized by very high bearing loads with few and relatively slow movements (e.g. cranes or nacelles of wind turbines), is the reduction of the starting torque. An external pressurized bearing is able to achieve this requirement. In order to establish fluid friction state the required pump power increases quadratically with increasing bearing load. This can lead to the conflict that the needed pump energy is higher than the energy savings caused in the reduction of friction torque. The investigated approach is to reduce the volume flow of this kind of bearings by use of greases instead of oils. 


\subsection{Rheology of greases}

Greases are characterized by non-Newtonian flow behavior due to their composition. The nonNewtonian flow behavior manifests itself as a presence of a certain yield stress as well as pseudoplastic flow behavior. In addition, they behave thixotropic. This means that their viscosity decreases with increasing shear time. The grease is therefore exposed to continuous wear during operation of the bearing. Due to the examined field of the thixotropy is neglected in the first instance. The two models in Fig. 1 are most commonly used to describe the flow behavior of greases [3].

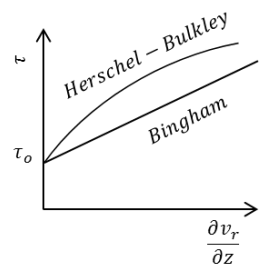

Figure 1: Commonly used flow models for greases

Bingham fluids include a certain yield stress but have constant viscosity after exceeding this yield point:

$$
\begin{array}{ll}
\tau=\tau_{o}+\eta \frac{\partial v_{r}}{\partial z} & \text { for } \tau>\tau_{0} \\
\frac{\partial v_{r}}{\partial z}=0 & \text { for } \tau \leq \tau_{0}
\end{array}
$$

The Herschel-Bulkley model incorporates the viscosity change with increasing shear rate. Pseudoplastic flow is determined with the exponent $\mathrm{n}<1$. For $\mathrm{n}=1$ we get the Bingham model again, for $\mathrm{n}>1$ the model behaves dilatant:

$$
\tau=\tau_{o}+k\left(\frac{\partial v_{r}}{\partial z}\right)^{n} \quad \text { for } \tau>\tau_{0}
$$

Previous studies by Horowitz and Steidler have already identified a number of advantages and disadvantages in the use of greases instead of Newtonian fluids in hydrostatic bearings coefficients [4]. These include:

- safety at low speeds,

- low side leakage,

- less sensitivity of load and friction to speed changes,

- existence of "cores" of plug flow,

- higher coefficients of friction.

Further investigations from Slibar et al. and Bradford et al. lead to the same conclusions [5],
[6]. The occurrence of unsheared cores on the increase of friction in slider bearings is mentioned by Milne [7]. The high age of the mentioned sources is particularly noticeable. The author's assumption is that this approach has not been pursued so far due to the disadvantages in the difficulty of designing and controlling greaselubricated external pressurized bearings, despite its advantages in lower leakage. The emergence of magnetorheological (MR) fluids, which exhibited Bingham flow behavior when applied by a magnetic field [8], has rekindled interest in the research of non-Newtonian flow behavior in hydrostatic bearings [9].

\subsection{Investigations on self-sealing behavior}

Considering axial slide bearing with a central pocket a cylindrical coordinate system is defined (Fig. 2):

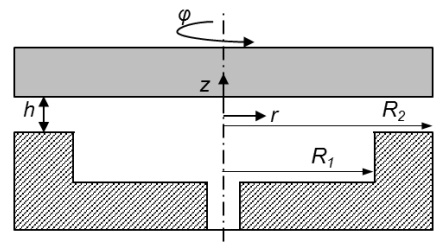

Figure 2: Defined coordinate system

The following assumptions are made for the derivation:

- validity of the Bingham model,

- time independence,

- rotationally symmetric flow,

- laminar flow,

- no rotation of the bearing,

- velocity gradient in the radial direction insignificant in comparison to z-direction.

These simplifications lead to the definition of an infinitesimal element with forces acting only in the radial direction in the sealing gap of the bearing (Fig. 3):

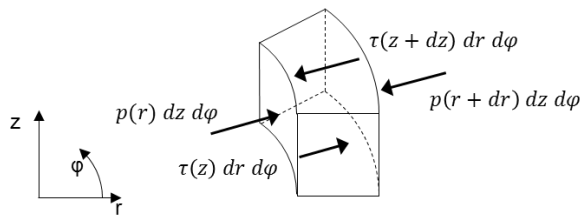

Figure 3: Acting forces in sealing gap 
The equilibrium of forces lead to:

$$
\begin{aligned}
& F_{r}=0=d z d \varphi(p(r)-p(r+d r)) \\
& +d r d \varphi(\tau(z)-\tau(z+d z))
\end{aligned}
$$

The Taylor series expansion results in:

$$
\begin{aligned}
& p(r+d r) \approx p(r)+\frac{\partial p}{\partial r} d r \\
& \tau(z+d z) \approx \tau(z)+\frac{\partial \tau}{\partial z} d z
\end{aligned}
$$

Applying of Eq. (5) and (6) in (4) forms to:

$$
\frac{\partial p}{\partial r}=-\frac{\partial \tau}{\partial z}
$$

The used Bingham model from Eq. (1) needs a negative sign due to the definition of the coordinate origin in the middle of the gap:

$$
-\tau=\tau_{o}+\eta \frac{\partial v_{r}}{\partial z} \quad \text { for }|\tau|>\tau_{0}
$$

The derivation of Eq. (8) after the gap height provides:

$$
-\frac{\partial \tau}{\partial z}=\eta \frac{\partial^{2} v_{r}}{\partial z^{2}}
$$

The insert of Eq. (9) in (7) provides the known differential equation for gap flow in hydrostatic bearings for the defined coordinate system:

$$
\frac{\partial p}{\partial r}=\eta \frac{\partial^{2} v_{r}}{\partial z^{2}}
$$

Subsequent integration across the gap height reveals the Bingham model:

$$
\frac{\partial p}{\partial r} z=\tau_{o}+\eta \frac{\partial v_{r}}{\partial z}
$$

The shear rate takes the value zero if the left term of the equation equals the yield stress $\tau_{0}$. The gap height variable for this can be defined as $\mathrm{z}_{0}$. The grease flows as unsheared core through the sealing gap at coordinates below this value. The absolute value bars make sure that this value is positive. Figure 4 illustrates this behavior.

$$
\left|\frac{\partial p}{\partial r}\right| z_{0}=\tau_{o}
$$

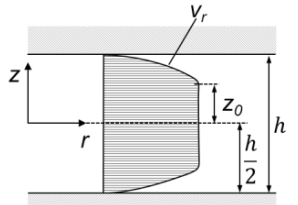

Figure 4: Unsheared core at sealing gap

In an axial sliding bearing with one central circular pocket the pressure drop across the sealing gap follows a logarithmic path. If the ambient pressure at the outlet is set to zero, the pressure can be expressed as:

$$
p=p_{p} \frac{\ln \left(\frac{R_{2}}{r}\right)}{\ln \left(\frac{R_{2}}{R_{1}}\right)}
$$

Accordingly, the pressure curve is:

$$
\frac{\partial p}{\partial r}=-\frac{p_{p}}{\ln \left(\frac{R_{2}}{R_{1}}\right) r}
$$

Insertion of Eq. (14) in (12) provides for each position $r$ the height of the unsheared core:

$$
z_{0}=\tau_{o} \frac{r}{p_{p}} \ln \left(\frac{R_{2}}{R_{1}}\right)
$$

This equation expresses a linear relationship between $z_{0}$ and $r$. If the height of the core corresponds at least to the sealing gap height $h$ before reaching the outlet, the fluid stops moving. This leads to the following definition for zero flow rate:

$$
z_{0} \geq \frac{h}{2}
$$

The use of this condition in Eq. 15 gives a maximum value for the induced pocket pressure. Fig. 5 illustrates this condition.

$$
p_{p} \leq 2 \tau_{\mathrm{o}} \frac{r}{h} \ln \left(\frac{R_{2}}{R_{1}}\right)
$$

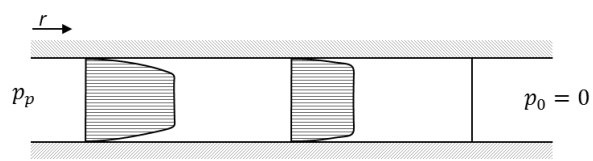

Figure 5: Progress of fluid velocity along the sealing gap at the inflow phase at zero flow rate condition. 
Exemplary for the presented hydrostatic thrust bearing $(\mathrm{R} 1=50 \mathrm{~mm}, \mathrm{R} 2=70 \mathrm{~mm})$, operating limits for leakage-free operation can be defined with this equation (17) (Fig. 6). The selected yield stress limits are based on common consistency classes of lubricating greases (NLGI 1 to NLGI 3). Values for the correlation between conus penetration and yield stress values are given by Cameron and Spiegel et al. [10], [11].

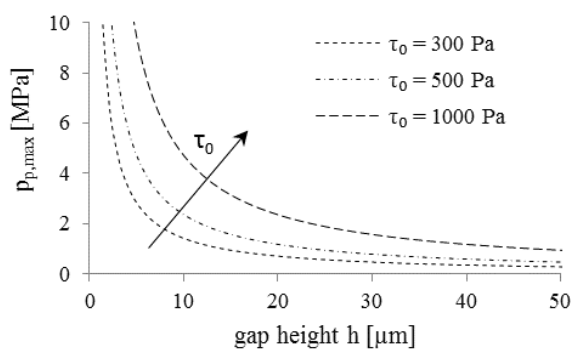

Figure 6: Limits for pocket pressure for leakage-free operation in static condition for exemplary thrust bearing

According to this diagram, NLGI grade 3 grease can be operated at a gap height of $10 \mu \mathrm{m}$ with a maximum of approx. $4 \mathrm{MPa}$. The manufacturing quality of the surfaces in the contact area requires high efforts to reach a fluid friction state at this kind of value. For more common gap heights of around $50 \mu \mathrm{m}$ the maximum pocket pressure drops to $1 \mathrm{MPa}$.

The presence of a stopping flow front could be determined for selected greases. Fig. 7 displays the flow front of a NLGI class 3 grease at the same pocket pressure and different sealing gap heights. Simulations by the use of a CFD model were also able to prove self-sealing behavior [12].
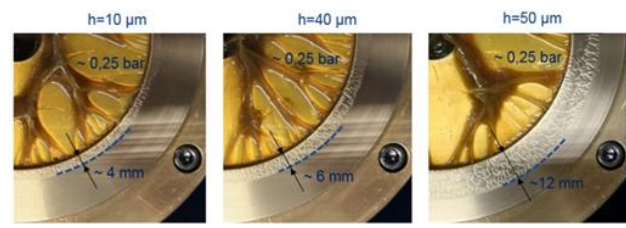

Figure 7: Proven self-sealing effect in a hydrostatic bearing for different gap heights

\subsection{Common lubrication gap control}

In classic hydrostatic bearings the lubrication gap height is controlled by the volume flow of the pump. An overview can be found in [13]. A distinction is made between three different control systems: one pump per bearing pocket, one pump and fixed restrictors for each pocket or one pump and adjustable restrictors. In all these systems the sealing gap height is regulated by the volume flow. Differences are found between the systems in the bearing stiffness. The stiffness of the hydrostatic bearing $K$ is defined as a quotient of force increase and bearing gap height change.

$$
K=-\frac{\Delta F}{\Delta h}
$$

The fixed restrictor system is characterized by the lowest stiffness due to a reducing flow rate with increased bearing. In contrast the configuration of the adjustable restrictors is theoretically able to gain a stiffness of infinity by an increasing volume flow. This is usually achieved with membrane restrictors. The system with one pump per bearing pocket lies between both systems, since the flow rate is kept almost constant. Because of the desired absence of volume flow in the described grease lubricated bearing configuration these control mechanisms cannot be used.

These control mechanisms can be referred to as passive controllers. In addition, there are concepts for active controllers that directly determine the lubrication gap height and then react with control signals in order to keep this value as constant as possible. Rehman et al. implement an active control of the lubrication gap of a hydrostatic journal bearing by servo valves [14]. Other researches focus on the use of magnetorheological fluids for an active gap control [9]. A constant lubrication gap is here achieved by the changes of the rheological properties of the magnetic fluids (viscosity and yield point) at constant flow rate by the insertion of a magnetic field.

\subsection{Research issue}

The mentioned control mechanisms cannot be used because of the intent to operate the greaselubricated bearings without a volume flow. The pressure transfer in greases behaves transient and is therefore difficult to control [15].

The aim of this investigation is the development of a new control system for grease lubricated hydrostatic bearings that allows the adjustment of different gap heights and reacts actively to changing bearing loads. The target is a bearing with an infinite stiffness. 


\section{RESEARCHED CONCEPT}

The presented solution bases on a separation into two functional areas by a flexible membrane (Fig. 8 ). The pressure transfer in order to control the hydrostatic compensation and a sealing gap height is ensured by an easy to regulate Newtonian fluid. The Newtonian fluid is led as close as possible to the bearing pocket. The actual lubricant in the bearing pocket is consistent grease. The grease is filled via an additional feed directly into the pocket. The chosen membrane is a rolling diaphragm with high stroke and diameter in order to have a large reservoir of lubricant.

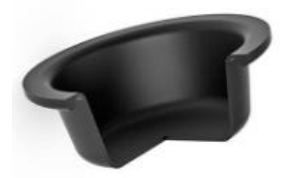

Figure 8: Used rolling diaphragm [16]

The operation steps of the bearing control can be explained accordingly to Fig. 9: a)

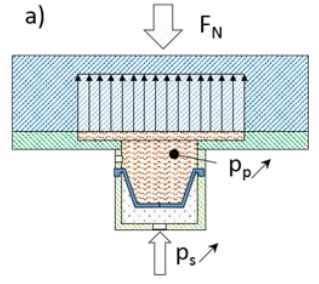

c)

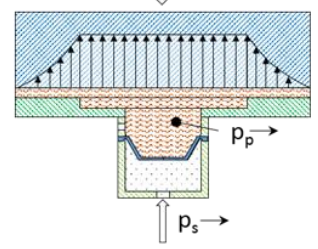

e)

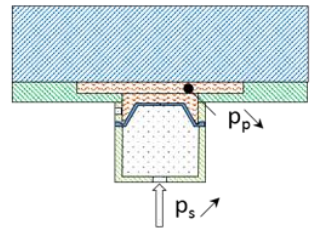

b) $\square \mathrm{F}_{\mathrm{N}}$

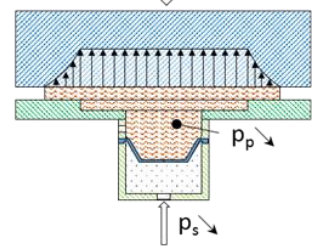

d)

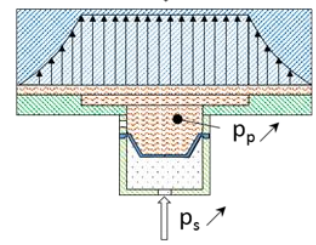

f)

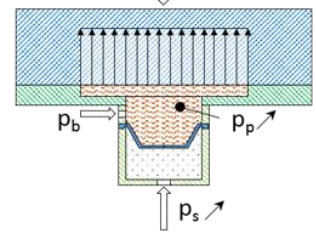

Figure 9: Functional steps of the bearing operation

a) The bearing is loaded by a normal force $F_{N}$. The pressure in the pocket $p_{P}$ is increased by the supply pressure $\mathrm{p}_{\mathrm{s}}$ until the resulting force in the pocket is just above the load force.

b) The upper bearing body lifts off after exceeding the balance of forces. As a result, the grease flows into the sealing gap. At constant pocket pressure, the resulting force would directly increase. Therefore, the supply pressure and with it the pocket pressure need to be reduced.

c) At reaching the desired gap height, the pressure must be kept constant. The resulting pressure force must be in the exact balance of forces with the load.

d) In case of a bearing load increase, the supply pressure must ideally be increased at the same time in order to ensure a constant sealing gap height. Likewise, when the load is reduced, the pressure must drop simultaneously.

e) If the gap height cannot be reduced in sufficient time, the maximum leakage is limited by the rolling diaphragm capacity. In the case of a complete exploitation of the diaphragms reservoir, its elastic resistance limits further pressure transfer. The pocket pressure drops in contrast to the supply pressure and the upper bearing element settles down.

f) An additional feed introduces new grease into the pocket (with pressure $\mathrm{p}_{\mathrm{b}}$ ) until the diaphragm is completely refilled.

\subsection{Control of the gap height}

For an active control of the sealing gap height the value of the height needs to be measured and the supply pressure must be actively controlled. The used concept can be explained by the schemata of the test bench in Fig. 10 and the control loop in Fig. 11.

The sealing gap height is measured with an inductive sensor directly in the sealing gap. The deviation $\Delta \mathrm{h}_{\mathrm{e}}$ from the desired setpoint value $\mathrm{h}_{\mathrm{i}}$ is transferred to a programmable software controller. The controller output is the supply pressure $\mathrm{p}_{\mathrm{s}}$. This supply pressure is adjusted with an electronically controlled pressure reducing valve. The maximum load capacity of the bearing results from the maximum available pressure provided by the pump. 


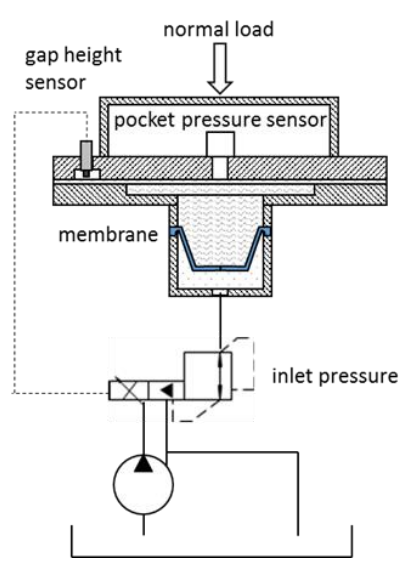

Figure 10: Configuration of the test bench

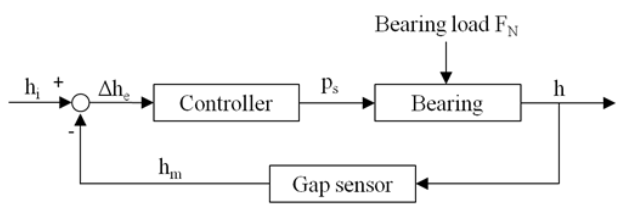

Figure 11: Control loop of the test bench

\section{EXPERIMENTAL INVESTIGATION}

At the test bench shown in Fig. 10 the control behavior for different lubricants under varying bearing loads was tested. Compressed air was used as pressure transfer medium. This means that the system was pneumatically controlled. The programmed software controller was a proportional plus integral type (PI controller). The decision was driven by a simple implementation. The main purpose of this study was initially a feasibility study of the sealing gap height control with this concept. Furthermore, the transfer on industrial applications in future becomes easier. The control parameters for each fluid were determined empirically due to a complex transfer function of this system.

\subsection{Tested fluids}

Two NLGI grade 2 non-Newtonian greases and one Newtonian oil were tested. Lubricating grease $\mathrm{A}$ is calcium soaped low-temperature grease with a thickener content of approx. $10-12 \%$. Grease B is a high-temperature grease based on bentonite with a thickener content of approx. 6-8 \%. The used Newtonian fluid is a commercially available CLP320 gear oil.

The values for yield stress and dynamic viscosity of the lubricating greases were determined at $20{ }^{\circ} \mathrm{C}$ in flow curve measurements by extrapolation. The value for the oil was calculated from the kinematic viscosity and the density. The determined values are summarized in Table 1.

Table 1: Tested fluids

\begin{tabular}{ccccc}
\hline Fluid & NLGI & $v\left[\mathrm{~mm}^{2} / \mathrm{s}\right]$ & $\tau_{0}[\mathrm{~Pa}]$ & $\eta[\mathrm{Pas}]$ \\
\hline Grease A & 2 & 14 & 205 & 0.053 \\
Grease B & 2 & 500 & 710 & 3.26 \\
CLP320 & - & 320 & - & 0.74 \\
\hline
\end{tabular}

\subsection{Test procedure}

In the first step the control parameters were determined empirically for each fluid by considering the step response to a defined sealing gap height. After the controller adjustment the behavior of the bearing for different sealing gap heights and increasing loads was tested. The dimensions of the tested axial thrust bearing and the selected control variables are diagramed below (Table 2 and 3 ).

Table 2: Bearing configuration

\begin{tabular}{ccc}
\hline Parameter & Value & Unit \\
\hline Inner diameter & 100 & $\mathrm{~mm}$ \\
Outside diameter & 140 & $\mathrm{~mm}$ \\
Pocket depth & 5 & $\mathrm{~mm}$
\end{tabular}

Table 3: Experimental setup

\begin{tabular}{ccccc}
\hline Parameter & Unit & Min. & Max. & Step \\
\hline Gap height & $\mu \mathrm{m}$ & 10 & 50 & 10 \\
Bearing load & $\mathrm{N}$ & 1000 & 3500 & 500 \\
\hline
\end{tabular}

\subsection{Results}

\section{Gap height adjustment}

Example curves in Fig. 12 express the adjustment behavior of the three fluids for a bearing load of $2000 \mathrm{~N}$ and a sealing gap height of $20 \mu \mathrm{m}$. Comparable behavior could be registered for other combinations of loads and sealing gap heights.

As explained in the functional description Fig. 12 indicate that an overpressure must first be 
generated in order to generate a lift of the upper bearing partner. In the greased bearing variants a much higher pressure is required than in the oil lubricated bearing. The most inert behavior can be registered for grease $\mathrm{B}$. The sealing gap initially continues to rise even when the pocket pressure is already reduced significantly. For this reason, the bearing tends to slightly overshoot.

The lubricating oil can be set the fastest to the required gap height, but at the same time it is the most sensitive towards disturbances.

In addition, the test reveals, that, despite of the same bearing load, the resulting pocket pressure differs for all three fluids.
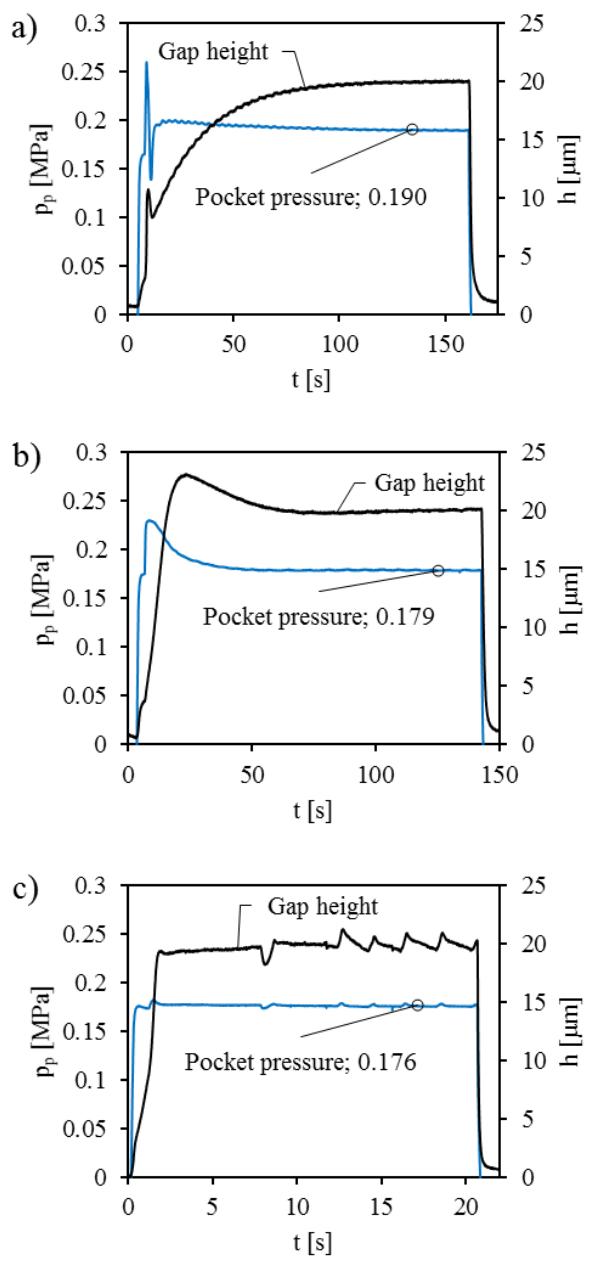

Figure 12: Time course of the adjustment of $20 \mu \mathrm{m}$ gap height at $2000 \mathrm{~N}$ load for Grease A (a), Grease B (b) and CLP320 (c)
The mean values from the resulting pocket pressures for different sealing gap heights $(10,20$ and $30 \mu \mathrm{m})$ and bearing load levels are plotted in Fig. 13. The calculated lines show the theoretically derived pocket pressures for Newtonian fluids for the used bearing geometry.
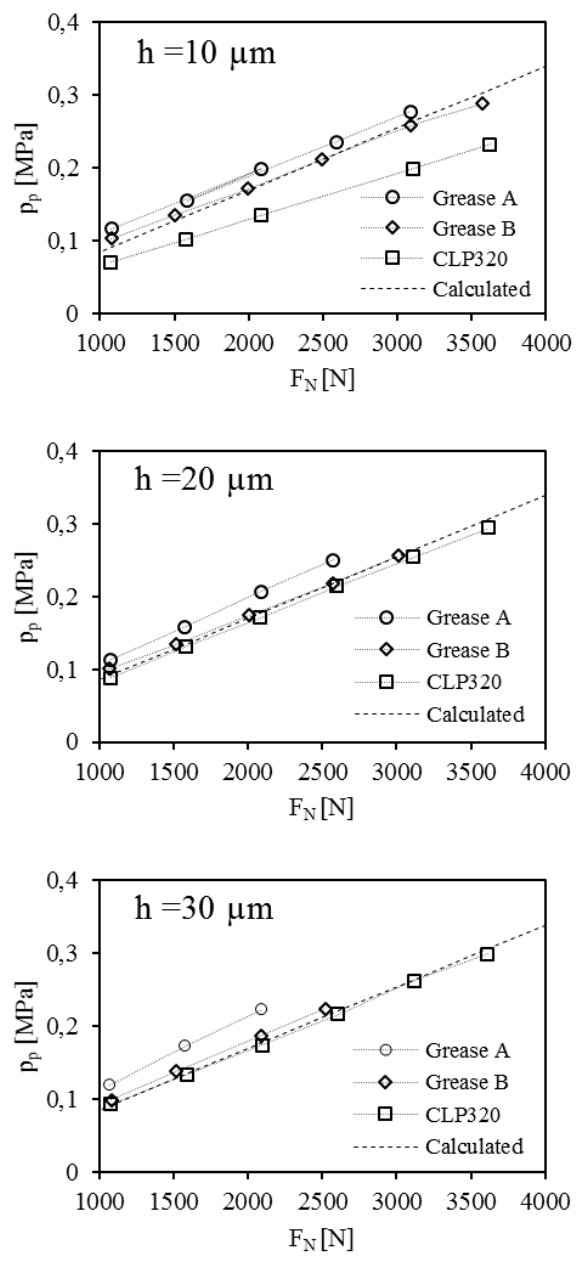

Figure 13: Steady state pocket pressures for different bearing load levels

At sealing gap heights of $20 \mu \mathrm{m}$ and $30 \mu \mathrm{m}$ the values determined for the oil correspond to the calculation. Higher values are registered for all loads for the grease-lubricated bearing. From this observation the following assumption can be settled: because of a higher decline of the pressure in the sealing gap with the use of grease, a higher pocket pressure must be applied to get 
the same resulting counterforce. At a sealing gap height of $10 \mu \mathrm{m}$, the values of Grease B and CLP320 oil are much lower than expected.

\section{Gap height stiffness}

When increasing the bearing loads $F_{N}$ for constant sealing gap heights $\mathrm{h}$ a similar behavior is observed as in the previous investigation. Grease B tends again to the most inert reaction (Fig. 14).
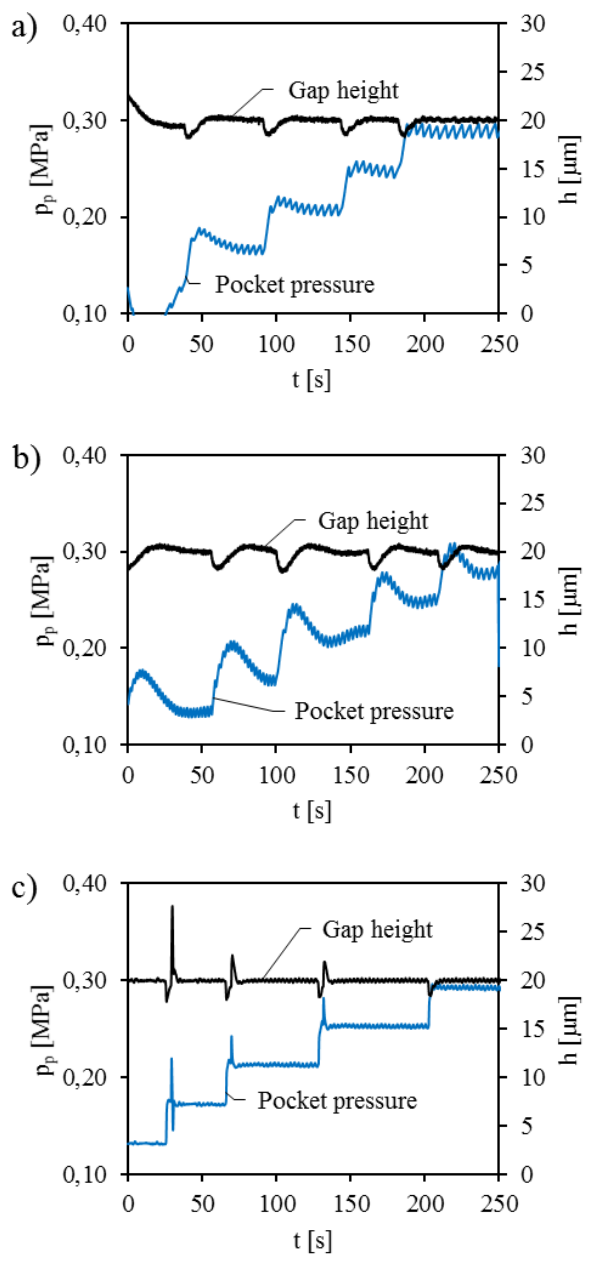

Figure 14: Control of a constant sealing gap height with increasing bearing load $\mathrm{F}_{\mathrm{N}}$ from 1500 $3500 \mathrm{~N}$ for Grease A (a), Grease B (b) and CLP320 (c)
The system becomes increasingly sensitive for increasing gap heights. The performance for Grease B at $40 \mu \mathrm{m}$ is shown in Fig. 15. The gap height drops down with a greater value by increasing the bearing load and the system requires more time to rebuild the desired lubrication gap to the inertia of the grease.

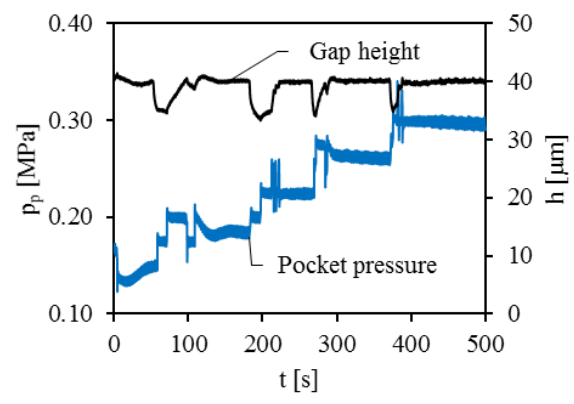

Figure 15: Control of a constant sealing gap height with increasing bearing load from 1500$3500 \mathrm{~N}$ for Grease B at $40 \mu \mathrm{m}$ gap height

\section{CONCLUSION AND OUTLOOK}

The results indicate that a pressure control via the rolling diaphragm in order to generate desired sealing gap heights at defined operating points is basically possible. For Newtonian oil sealing gaps could be reproduced with an accuracy of $\pm 0.25 \mu \mathrm{m}$, grease A with an accuracy around $\pm 0.35 \mu \mathrm{m}$ and the more inert grease B around $\pm 0.5 \mu \mathrm{m}$.

In a stationary view, an infinite stiffness for all three fluids can be proven with this control concept until the maximum supply pressure is reached. At a time perspective, collapses are noticeable in the event of a load change. Depending on the used fluid and the sealing gap height, the collapses vary in magnitude and are compensated at different speeds. This behavior strongly depends on the selected controller and the control parameters.

In addition to the bearing geometry, the rheology of the bearing fluid has a major impact on the controlled system. Due to its linearity, the Bingham model can reproduce the flow behavior with sufficient accuracy only in a defined operating point. The thixotropy and pseudoplasticity behavior are not considered within this model but can have an important impact on the gap control. Advanced models such 
as the Herschel-Bulkley or Sisko model include pseudoplasticity, but do not allow analytical solutions [3] .

Another influence on the control behavior could be the occurrence of wall slip [17]. This wall-slip effect can be responsible for the fact that, despite falling below the pressure gradient in the sealing gap and thus the assumption of selfsealing it comes to a flow of an unsheared cores at the wall boundaries.

Nonlinear controllers, such as adaptive controllers or optimal controllers [18], could be able to hold the grease-operated bearings stable at desired working heights even at different operating points. The presented test bench allows the use of different types of controller for closer examination in the future.

Grease A indicates the best performance in terms of tendency to leakage, regulation of the gap height and friction reduction. In previous investigations of the friction torque Grease A achieved comparable friction coefficients as the CLP320 oil, shown in Fig. 16.

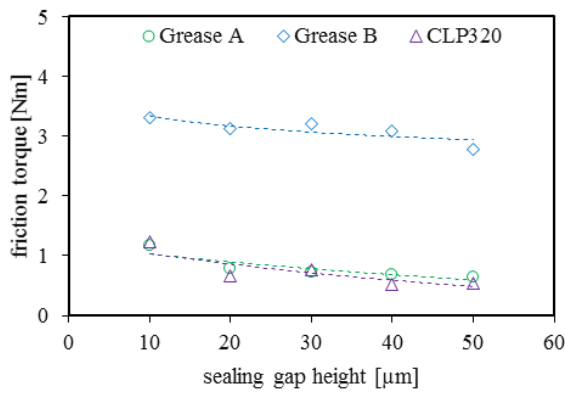

Figure 16: Tested sliding frictions for different gap heights at a bearing load of $1500 \mathrm{~N}$

\section{NOMENCLATURE}

$F_{N} \quad$ Normal force, bearing load

$h \quad$ Sealing gap height

$p_{p} \quad$ Pocket pressure

$p_{s} \quad$ Supply pressure

$p_{b} \quad$ Bypass pressure

$\eta \quad$ Dynamic viscosity

$\tau \quad$ Shear stress

$\tau_{0} \quad$ Yield stress

\section{REFERENCES}

[1] O’Donoghue J, Rowe W (1969) Optimization of Hydrostatic Bearings for Minimum Power and Low Temperature Rise. Industrial Lubrication and Tribology, Vol. 21, 101 -108

[2] Hamrock B.J, Schmid S.R, Jacobson B.O (2004) Fundamentals of Fluid Film Lubrication. 2nd ed., New York, Dekker

[3] Kuhn E (2017) Zur Tribologie der Schmierfette, Renningen, Expert Verlag

[4] Horowitz H.H, Steidler F.E (1963) Calculated Performance of Greases in Journal Bearings. ASLE Transactions, 239-248

[5] Slibar A, Pasley P.R. (1957) On the Theory of Grease Lubrication Studies in Plain Journal Bearings. ASME Trans. 79, 1229-1234

[6] Bradford L.J, Barber E.M, Muenger P.J (1961) Grease Lubrication Studies in Plain Journal Bearings. J. Basic Eng. ASME Trans. 81, 153-161

[7] Milne A.A (1964) A theory of Grease Lubrication of a Slider Bearing. Proceedings of the Second International Congress on Rheology, New York, Academic Press, 427-436

[8] Butz T, von Stryk O (2002) Modelling and Simulation of Electro- and Magnetorheological Fluid Dampers. ZAMM Vol. 82, No. 1, 3-20

[9] Abel-Keilhack C, Hesselbach J (2003) Active hydrostatic bearing with magnetorheological fluid. Journal of applied physics, 8441-8443

[10] Cameron A (1966) The Principles of Lubrication. London, Longmans Green and Co. Ltd.

[11] Spiegel K, Fricke J, Meis K.R (2000) Das Fließverhalten von Schmierfetten. Schmierfette: Zusammensetzung, Eigenschaften, Prüfung und Anwendung. Renningen, Expert Verlag, 228-265

[12] Mass I, Hoppermann A, Murrenhoff H (2018) Pressure distribution of greases in hydrostatic bearings under static conditions. Fluid power networks : proceedings : 19th - 21th March 2018 : 11th International Fluid Power Conference, Vol. 3, 68-77

[13] Weck M, Brecher C (2019) Werkzeugmaschinen - Fertigungssysteme 1. Berlin, Springer Vieweg

[14] Rehman W.U, Yuanxin L, Guiyun J, Yongqin W, Yun X, Iqbal M.N, et al (2017) Control of an oil film thickness in a hydrostatic journal bearing under different dynamic conditions. Proceedings of the 29th Chinese control and 
decision conference (CCDC), Chongqing, China, 28-30 May 2017, 5072-5076

[15] Oliveira G.M, Negrão C.O, Franco A.T (2011) Pressure transmission in Bingham fluids compressed within a closed pipe. Journal of Non-Newtonian Fluid Mechanics, 121-125

[16] Freudenberg Sealing Technologies, [Online]. Available:

https://www.fst.com/products/special-sealingproducts/diaphragms. [Access on 11 Nov 2019].

[17] Westerberg L, Lundström T.S, Höglund E, Lugt P.M (2010) Investigation of Grease Flow in a Rectangular Channel Including Wall Slip Effects Using Microparticle Image Velocimetry. Tribology Transactions, 53:4, 600-609

[18] Iqbal J, Ullah M, Khan S.G, Khelifa B, Ćuković S (2017) Nonlinear control systems - A brief overview of historical and recent advances. Nonlinear Engineering 6(4) 